\title{
Bilateral bisphosphonate-related osteonecrosis of the jaw with left chronic infection in an 82-year-old woman
}

\author{
Laure Gallay, ${ }^{1}$ Anne-Gaëlle Bodard ${ }^{2}{ }^{2}$ Christian Chidiac, ${ }^{1,3,4,5}$ Tristan Ferry $^{1,3,4,5}$
}

\begin{abstract}
${ }^{1}$ Hospices Civils de Lyon, Lyon, France

${ }^{2}$ Unité d'Odontologie, Service de Chirurgie, Centre Régional de Lutte Contre le Cancer, Centre Léon-Bérard, Lyon, France

${ }^{3}$ Université Claude Bernard Lyon 1, Lyon, France ${ }^{4}$ Centre International de Recherche en Infectiologie, CIRI, Inserm U1111, CNRS UMR5308, ENS de lyon, UCBL1, Lyon, France

${ }^{5}$ Centre Interrégional de Référence Rhône-Alpes Auvergne des Infections Ostéo-articulaires complexes, Hospices Civils de Lyon, France
\end{abstract}

\section{Correspondence to} Dr Tristan Ferry, tristan.ferry@univ-lyon1.fr

\section{To cite: Gallay $\mathrm{L}$,} Bodard A-G, Chidiac C, et al. BMJ Case Rep Published online: [please include Day Month Year] doi:10.1136/bcr-2013008558

\section{DESCRIPTION}

An 82-year-old woman, treated for severe rheumatoid polyarthritis by tumour necrosis factor inhibitors (2003-2008), rituximab (2008), abatacept (20082011) and long-term steroid therapy, also received prolonged bisphosphonate therapy to prevent bone mass loss. In 2009, a bilateral bisphosphonate severe osteonecrosis of the jaw (BONJ) was discovered along with evidence of left chronic mandible infection in early 2012, as mucosal disruption and suppurative sinus tract occurred (figure $1 \mathrm{~A}, \mathrm{~B}$ ). Bisphosphonate was stopped and mild surgical debridement was performed. Despite administration of antimicrobial therapy including high dose of amoxicillin and fluconazole, the suppurative sinus tract persisted. As a left mandibular fracture with significant mouth opening reduction was spontaneously carried out, a radical surgery, consisting of complete hemi-mandibular resection without reconstruction, was performed. Surgical bone sampling revealed Actinomyces naeslundi in cultures, and prolonged amoxicillin therapy was administered. During the follow-up, the outcome was favourable without recurrence of the suppuration (figure 1C,D).

The pathogenesis of BONJ is not well known. ${ }^{1}$ Some risk factors have been identified, such as the route of administration or the duration use of bisphosphonate, the concomitant administration of corticosteroids and performance of dental invasive procedures. ${ }^{1}$ BONJ may be owing to: (1) osteoclast inhibition and antiangiogenic effect of bisphosphonate, resulting in oversuppression of bone turnover and avascular necrosis; (2) bisphosphonate mucosal toxicity leading to mucosal disruption and (3) involvement of Actinomyces species in biofilm in bone. ${ }^{12}$ BONJ with evidence of chronic infection is associated with severe morbidity, required adequate surgery (debridement or more aggressive surgery) and prolonged antimicrobial treatment targeting Actinomyces. ${ }^{1-3}$

\section{Learning points}

Bilateral bisphosphonate severe osteonecrosis of the jaw:

- Occur mainly in patients with several risk factors, such as age and coadministration of corticosteroid therapy.

- Is due to bisphosphonate toxicity, but there is some evidence that bone colonisation by Actinomyces species in biofilm participate to the pathogenesis.

- Could be associated with evidence of infection, requiring surgery and prolonged antimicrobial therapy targeting Actinomyces species.
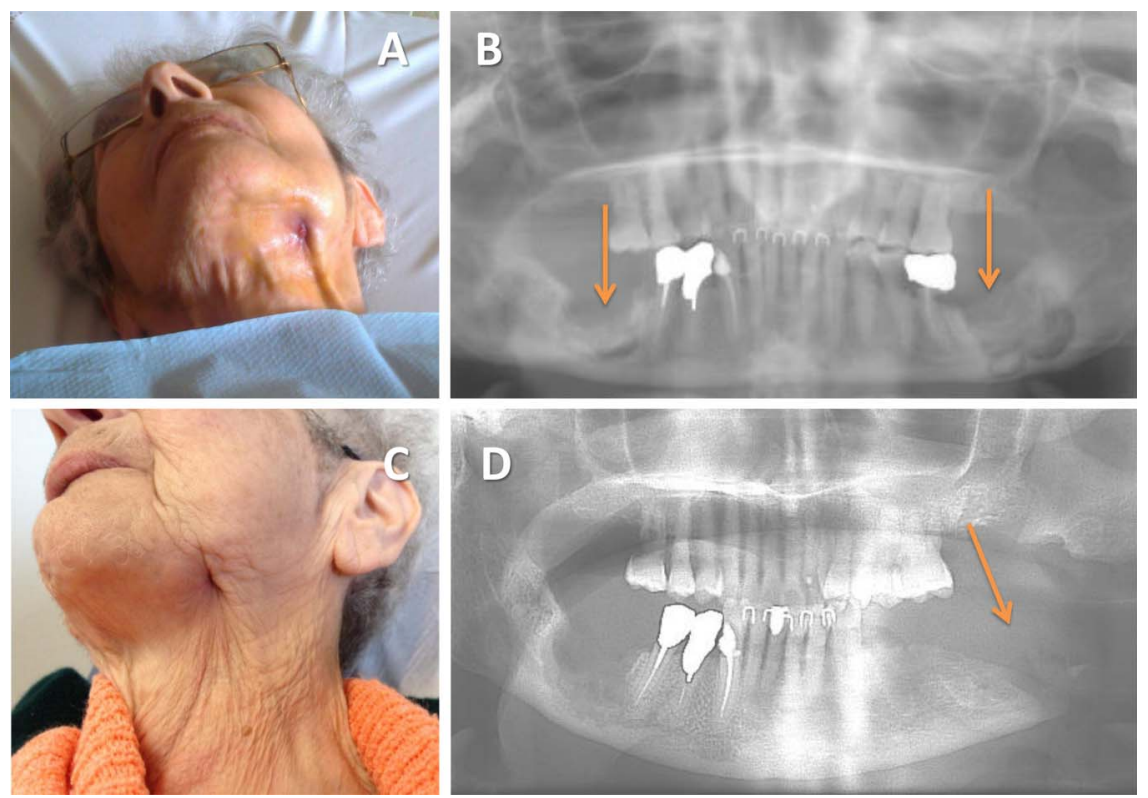

Figure 1 Bilateral bisphosphonate severe osteonecrosis of the jaw with suppurative sinus tract $(A)$. The orthopantomographic view revealed bilateral severe osteonecrosis ( $B$, arrows). After radical surgery and prolonged amoxicillin therapy, the outcome of the infection was favourable without recurrence of the suppuration (C). The orthopantomographic view after complete hemi-mandibular resection with dental extractions and without reconstruction ( $D$, arrow). 
Acknowledgements Pr Pierre Breton, who participated in the patient care and our colleagues from the Lyon Bone and Joint Infection Study Group. Physicians: Tristan Ferry, Thomas Perpoint, André Boibieux, François Biron, Florence Ader, Anissa Bouaziz, Judith Karsenty, Fatiha Daoud, Johanna Lippman, Evelyne Braun, Marie-Paule Vallat, Patrick Miailhes, Florent Valour, Christian Chidiac, Dominique Peyramond; Surgeons: Sébastien Lustig, Franck Trouillet, Philippe Neyret, Olivier Guyen, Gualter Vaz, Christophe Lienhart, Michel-Henry Fessy, Cédric Barrey;

Microbiologists: Frederic Laurent, François Vandenesch, Jean-Philippe Rasigade; Nuclear Medicine: Isabelle Morelec, Emmanuel Deshayes, Marc Janier, Francesco Giammarile; PK/PD specialists: Michel Tod, Marie-Claude Gagnieu, Sylvain Goutelle; Clinical Research Assistant: Marion Martinez.

Competing interests None.
Patient consent Obtained.

Provenance and peer review Not commissioned; externally peer reviewed.

\section{REFERENCES}

1 Advisory Task Force on Bisphosphonate-Related Ostenonecrosis of the Jaws, American Association of Oral and Maxillofacial Surgeons. American Association of Oral and Maxillofacial Surgeons position paper on bisphosphonate-related osteonecrosis of the jaws. J Oral Maxillofac Surg 2007;65:369-76.

2 Naik NH, Russo TA. Bisphosphonate-related osteonecrosis of the jaw: the role of actinomyces. Clin Infect Dis 2009;49:1729-32.

3 Magopoulos C, Karakinaris G, Telioudis Z, et al. Osteonecrosis of the jaws due to bisphosphonate use. A review of 60 cases and treatment proposals. Am J Otolaryngol 2007;28:158-63.

Copyright 2013 BMJ Publishing Group. All rights reserved. For permission to reuse any of this content visit http://group.bmj.com/group/rights-licensing/permissions.

BMJ Case Report Fellows may re-use this article for personal use and teaching without any further permission.

Become a Fellow of BMJ Case Reports today and you can:

- Submit as many cases as you like

- Enjoy fast sympathetic peer review and rapid publication of accepted articles

- Access all the published articles

- Re-use any of the published material for personal use and teaching without further permission

For information on Institutional Fellowships contact consortiasales@bmjgroup.com

Visit casereports.bmj.com for more articles like this and to become a Fellow 